\title{
Sección: Política Internacional Introducción
}

Lía Rodríguez de la Vega

Una de las circunstancias políticas que concentraron la atención del mundo este año fue la del llamado "Brexit" (contracción entre los términos Britain y exit) para denominar la salida del Reino Unido de la Unión Europea.

Tal medida, como sabemos, surge como resultado de un referéndum realizado el 23 de junio para decidir si el Reino Unido debía dejar o continuar formando parte de la Unión Europea, en el cual quienes optaron por dejarla representaban al $52 \%$ de la población que votó, más de 30 millones de personas.

Sin embargo, esa decisión estuvo lejos de ser homogénea. Así, mientras en Inglaterra, el 53,4 \% votó por dejar la Unión Europea, de igual modo que sucedió en Gales (en donde la mayoría representó el 52,5 \% de los votos), en Escocia e Irlanda del Norte, la mayoría votó por permanecer en la Unión Europea (62 \% de los votos en Escocia y 55,8 $\%$ en Irlanda del Norte), con las consiguientes tensiones al interior del Reino Unido (BBC News, 2016).

Tras el referéndum, un día después del mismo, renunció el entonces Primer Ministro, David Cameron, que sostuvo la campaña por la permanencia en la Unión Europea y sería reemplazado por la nueva Primer Ministro, Theresa May.

May, al igual que su predecesor, votó por la permanencia en la Unión y ha sostenido que más allá del respeto por la voluntad popular, queda discutir cómo se traduce "Brexit" en la práctica, especialmente en lo que concierne al modo como las empresas británicas harán negocios en la Unión Europea y al tema de los derechos de los nacionales europeos para vivir y trabajar en el Reino Unido. A todo ello, por supuesto, se suma la dinámica misma de la relación entre el Reino Unido y la Unión Europea (Foster, 2016; Trianor, 2016).

En el plano económico, donde muchos habían vaticinado un impacto inmediato y duro, el mismo parece haber resistido el embate previsto, aun cuando es justo decir que el valor de la libra se mantiene como el más bajo en los últimos 30 años y las opiniones acerca de los efectos a mediano y largo plazo permanecen divididas (BBC News, 2016b).

Por otro lado, otra circunstancia que cobró notoriedad en el mundo es la del fallo dado por la Corte Permanente de Arbitraje en La Haya, que debía decidir, a instancias de la presentación de Filipinas, las disputas que han acrecentado las tensiones por la soberanía en una zona que resulta crucial para el comercio mundial (de las que también participan Brunei, Malasia, Taiwán y Vietnam), sobre la base técnica de las disputas territoriales en el mar del Sur de China. El tribunal favoreció los reclamos de Filipinas y negó base legal a los argumentos de China para 
atribuirse la soberanía del $90 \%$ de las aguas de ese mar, señalando además que considera que China violó los derechos de soberanía de Filipinas, perjudicó el medioambiente y también los derechos que los pescadores filipinos comparten con los chinos.

Más allá de lo mencionado, el elemento que más concitó la atención fue la inesperada decisión reflejada en el fallo de negar carácter de isla al islote de Itu Aba, o Taiping, bajo control taiwanés, que queda de este modo definido como una simple "roca", no pudiendo así generar derecho a una zona económica exclusiva de 200 millas marinas para China.

Mientras China ya señaló que no reconoce ni acepta el citado fallo, se abren las consideraciones acerca de las consecuencias de un posible endurecimiento de las tensiones en la región, con alcances para el resto del mundo (por ejemplo, aumentos en los costos de los seguros por comercio de los bienes que atraviesan la zona, la presión sobre el resto de los países para tomar posición al respecto, etc.) (Arana, 2016; Hunt, 2016; Phillips, Holmes y Bowcott, 2016).

Ambos temas, de absoluta actualidad y con los alcances mencionados aún en desarrollo, son abordados por los autores que participan en la sección en este número: Eduardo Samuel Torres Espinosa (Universidad de los Andes, Venezuela) y María Cecilia Peralta (UBA, UNTreF, Co-fundadora de AsiaViewers) y Nadia G. Radulovich (USAL, Universidad de Tamkang, Co-fundadora de AsiaViewers).

\section{Referencias Bibliográficas}

ARANA, I. (2016). La Haya falla que Pekín no tiene "derechos históricos" en el mar de la China Meridional. El Mundo. Asia (12 de julio). Recuperado de http://www.elmundo.es/internacional/2016/07/12/5784b444468aeb3e458b461c.html

BBC News (2016). EU Referendum. Results. BBC News (1· de septiembre). Recuperado de http://www.bbc.com/news/politics/eu referendum/results

BBC News (2016b). Brexit Britain: What has actually happened so far? BBC News (5 de septiembre). Recuperado de http://www.bbc.com/news/business-36956418

FOSTER, P. (2016). Five reasons why the EU will make life impossible for Theresa May after Brexit - and five reasons why it should think again. The Telegraph News (20 de septiembre). Recuperado de http://www.telegraph.co.uk/news/2016/09/20/five-reasons-why-europe-will-make-life-impossible-for-theresa-ma/ 
HUNT, K. (2016). Un tribunal de La Haya falla que China violó los derechos de soberanía de Filipinas. CNN Asia (12 de julio). Recuperado de http://cnnespanol.cnn.com/2016/07/12/un-tribunal-de-la-haya-falla-que-china-violo-losderechos-de-soberania-de-filipinas/

PHILLIPS, T; HOLMES, O. \& BOWCOTT, O. (2016). Beijing rejects tribunal's ruling in South China Sea case. Xi Jinping says China's 'territorial sovereignty and marine rights' in the seas will not be affected. The Guardian. South China Sea (12 de julio). Recuperado de https://www.theguardian.com/world/2016/jul/12/philippines-wins-south-china-seacase-against-china

TRIANOR, J. (2016). 'Significant' risk to UK firms if passporting rights lost after Brexit. Treasury publishes FCA data showing over 8,000 companies authorised in other EU states use these rules to do business in UK. The Guardian. Financial Sector (20 de septiembre). Recuperado de http://www.theguardian.com/politics/2016/sep/20/passporting$\underline{\text { rights-brexit-uk-firms-fca-eu }}$ 